\title{
Dimensions of Negative Thinking and the Relations with Symptoms of Depression and Anxiety in Children and Adolescents
}

\author{
Lea Rood · Jeffrey Roelofs · Susan M. Bögels • \\ Lauren B. Alloy
}

Published online: 29 July 2009

(C) The Author(s) 2009. This article is published with open access at Springerlink.com

\begin{abstract}
The current study sought to examine three forms of negative, repetitive thinking in non-clinical children and adolescents aged between 10 and 18. More specifically, this study addressed the degree to which stress-reactive rumination can be differentiated from other forms of repetitive thinking, such as emotion-focused rumination and worry, and the associations between the various indices of repetitive thinking and symptoms of anxiety and depression. Participants completed a battery of self-report questionnaires including measures of stressreactive rumination, emotion-focused rumination, worry, and symptoms of anxiety and depression. Results showed that stress-reactive rumination, emotion-focused rumination and worry are related but distinct forms of repetitive negative thinking. Positive associations were found between all indices of repetitive thinking and symptoms of depression and anxiety, but the effects of emotion-focused rumination disappeared when controlling for the other forms of repetitive thinking. The findings are discussed in the light of current theories and previous research, and directions for future research are provided.
\end{abstract}

Keywords Anxiety - Depression - Repetitive thinking · Rumination · Worry

L. Rood $(\bowtie) \cdot$ J. Roelofs

Department of Clinical Psychological Science, Maastricht University, P.O. Box 616, 6200 MD Maastricht, The Netherlands e-mail: L.Rood@maastrichtuniversity.nl

S. M. Bögels

Department of Education, University of Amsterdam, Amsterdam, The Netherlands

L. B. Alloy

Temple University, Philadelphia, PA, USA

\section{Introduction}

Unconstructive forms of repetitive thinking may represent a cognitive vulnerability factor implicated in the development and maintenance of various emotional disorders such as anxiety disorders and depression (e.g., Watkins 2008). More specifically, repetitive thinking characterized by negatively valenced thought content (e.g., thoughts about depressive or anxious mood), a negative intrapersonal context (e.g., negative mood or negative self-beliefs), and an abstract level of construal (i.e., thinking about meanings and implications) is thought to contribute to negative mood states. In the literature, different types of repetitive thinking are distinguished, with their own conceptualizations and qualities. Emotion-focused rumination is considered a predominantly unconstructive form of repetitive thinking (see Watkins 2008), which involves repetitive thoughts about depressive symptoms and the causes and consequences of these symptoms (e.g., Nolen-Hoeksema 1987). According to the response styles theory (e.g., NolenHoeksema 1987, 1991, 1998), engaging in emotionfocused rumination is related to amplified and prolonged periods of depression in adults (see for comprehensive reviews Lyubomirsky and Tkach 2004; Nolen-Hoeksema 1998). In youth, emotion-focused rumination is positively associated with concurrent levels of depressive symptoms (e.g., Abela et al. 2004; Muris et al. 2004; Papadakis et al. 2006) and may predict increases in depressive symptoms over time (e.g., Abela et al. 2002, 2007; Burwell and Shirk 2007; Schwartz and Koenig 1996).

Stress-reactive rumination is another form of repetitive thinking that has been introduced by Alloy et al. (2000), Robinson and Alloy (2003), as an extension of the response styles theory. More specifically, stress-reactive rumination involves the tendency to ruminate on negative inferences 
following stressful events (Robinson and Alloy 2003). The content of stress-reactive thoughts is consistent with hopelessness theory (Abramson et al. 1989), but is somewhat different from dysfunctional attitudes (Beck 1967) that may be focused on beliefs that their happiness depends on being perfect or others' approval (see Robinson and Alloy 2003). That is, stress-reactive rumination involves the process of repetitively thinking about negative inferences in response to the occurrence of stressful events. As emotion-focused rumination was theoretically linked to the maintenance of depressive symptoms, stress-reactive rumination has been developed to explain the onset of depressive symptoms. There is indeed some evidence to suggest that stress-reactive rumination, in combination with negative cognitive style, contributes to the onset of depression in adults, and that stress-reactive rumination may be an even more consistent predictor of the onset and duration of depressive symptoms than emotion-focused rumination in adults (Alloy et al. 2000; Robinson and Alloy 2003). However, to the authors' best knowledge, there have been no systematic attempts to examine stress-reactive rumination in relation to symptoms of psychopathology in youth.

Worry is yet another form of repetitive negative thinking and can be defined as a chain of thoughts and images that are negatively affect-laden and relatively uncontrollable (Borkovec et al. 1983; Roemer and Borkovec 1993). Although worry has problem-solving qualities (e.g., Borkovec et al. 1983), excessive worrying has been considered a key element of generalized anxiety disorder (American Psychiatric Association 2000), but has also been found to play a role in other anxiety problems such as obsessive-compulsive disorder, social phobia, and panic disorder (e.g., Borkovec 1994; Dugas et al. 1998; Muris 2007). In youth, high levels of worry seem to be associated with more anxiety symptoms (e.g., Weems et al. 2000) and the level of induced panic symptoms (e.g., Leen-Feldner et al. 2006). Research with clinically anxious youth has demonstrated that worry is not only present in generalized anxiety disorder, but also in separation anxiety disorder and social phobia (e.g., Perrin and Last 1997; Weems et al. 2000).

Another important issue is the relationship between the different forms of repetitive thought and symptoms of depression and anxiety. So far, most research has focused on the relationships between emotion-focused rumination and worrying on the one hand, and symptoms of depression and anxiety on the other hand. In keeping with the notion that emotion-focused rumination and worry can be considered transdiagnostic variables (e.g., Harvey et al. 2004), there is evidence to suggest that both forms of negative repetitive thinking are related to both anxiety and depression symptoms in adults (e.g., Blagden and Craske 1996;
Fresco et al. 2002; Molina et al. 1998; Muris et al. 2005; Nolen-Hoeksema 2000; Roberts et al. 1998; Sarin et al. 2005; Starcevic 1995; Watkins 2004) and youth (e.g., Calmes and Roberts 2007; Fresco et al. 2002; Hong 2007; Muris et al. 2004; Segerstrom et al. 2000). To date, there is no research that has examined whether stress-reactive rumination is a transdiagnostic variable in terms of relations with both symptoms of anxiety and depression.

Taken together, from a theoretical and conceptual point of view, emotion-focused rumination, stress-reactive rumination, and worry represent three dimensions of negative thinking that have a certain degree of overlap, particularly with respect to being unconstructive repetitive thoughts. Despite the overlap, a number of studies have addressed the extent to which emotion-focused rumination and worry can be distinguished (Fresco et al. 2002; Muris et al. 2004; Watkins et al. 2005). Factor analytic studies have revealed that emotion-focused rumination and worry are related, but distinct, as they load on different intercorrelated factors (see Fresco et al. 2002; Muris et al. 2004). Several other researchers have failed to find as much difference between emotion-focused rumination and worry (e.g., Segerstrom et al. 2000; Watkins et al. 2005), where the only difference found was temporal orientation, with emotion-focused rumination focused on the past and worry focused on the future. To date, there are no factor analytic studies that have investigated the degree of distinctiveness between stress-reactive rumination and other forms of repetitive thinking. The aim of the present study was to examine whether stress-reactive rumination is an independent form of negative repetitive thinking by means of a joint exploratory factor analysis comprising the items from three self-report scales of emotion-focused rumination, stress-reactive rumination, and worrying, respectively, in children and adolescents. Given important developmental differences such as the emergence, stabilization, and crystallization of cognitive vulnerability factors for depression between younger and older participants (see Abela and Hankin 2008), we conducted two separate factor analyses in the younger sample (ages 10-13) and the older sample (ages 14-18). The second aim of this study was to examine cross-sectional relations between stress-reactive rumination, and symptoms of depression and anxiety. The extent to which the three forms of repetitive thinking were related to symptoms of depression and anxiety was investigated by assessing the association with and without controlling for the effects of the other forms of repetitive thinking, age, gender, and for concurrent anxiety/depression symptoms. From a transdiagnostic perspective, we hypothesized that all three dimensions (i.e., emotionfocused rumination, stress-reactive rumination and worrying) would account for a significant portion of the variance in symptoms of depression and anxiety. 


\section{Methods}

Participants and Procedure

Two samples were used in the current study. Participants of sample one were recruited at primary and secondary schools in the southern regions of The Netherlands. First, principals of schools were approached and informed about the purpose of the study. When given permission to recruit at their school, the researchers came into the classrooms during regular class and held a 10-min talk in front of all pupils. The purpose of the study was explained as 'examining the influence of the way teenagers think on what they feel'. Subsequently, informed consent forms were handed out and returned 2 weeks later. Response rates varied somewhat per school. On average, $25 \%$ of the youngsters who were approached agreed to participate in a 3-year longitudinal study. There was no compensation in turn for participation. Written informed consent was obtained from all parents and from the children where appropriate. A total number of 805 participants (323 boys and 482 girls) completed the baseline measurement of the longitudinal study. Of these individuals, some had more than $10 \%$ missing values on one of the measures included in the current study and were therefore excluded for that specific measure. As a consequence, sample size ranged between 779 and 805 across the various analyses. The mean age of the sample was $12.4(\mathrm{SD}=1.9)$, ranging from 10 to 18 . Ethnicity was not reported but it is estimated that about 95\% of the sample were Caucasian. Participants completed a battery of questionnaires at home, as part of a 3-year follow-up study. Participants could indicate whether they preferred completing the questionnaires on the internet or on paper. The majority (78.3\%) filled in the questionnaires on the internet and the remaining $21.7 \%$ preferred the paper-and-pencil version. The proportion of the sample that exhibited clinically significant levels of depressive symptoms was $12.9 \%$ (CDI cut off score $\geq 16$; see Timbremont et al. 2004). As for clinical levels of trait anxiety symptoms, $7.5 \%$ of the girls and $8.4 \%$ of the boys scored above the cut off scores of two standard deviations above the mean (STAIC cut off score for girls $\geq 46$; for boys $\geq 42$; see Bakker et al. 1989).

For the purpose of the factor analysis, data from a second sample which also completed the three questionnaires assessing negative repetitive thinking (see "Measures"), was used and combined with sample one. In the second sample, a total of 801 children and adolescents ( 367 boys and 434 girls) with a mean age of 12.9 years $(S D=2.1$, age range $10-18$ years) participated. The vast majority of the youth $(>95 \%)$ were Caucasian. The self-report measures were completed during regular class time. The teacher and a research assistant were available to answer questions and to ensure confidential responding. Response rates were higher $(40 \%)$, which is probably due to the difference in commitment to a study with a single measurement and with three waves. The combined dataset resulted in two groups of 1,078 children aged 10-13, and 528 adolescents aged $14-18$.

\section{Measures}

\section{Repetitive Negative Thinking}

The children's response styles scale (CRSS; Ziegert and Kistner 2002; Dutch version: Muris et al. 2004) is a selfreport questionnaire that measures the tendency to ruminate and the tendency to seek distraction in response to feelings of sadness in children. The CRSS consists of 20 items and is based on the response styles questionnaire for adults (RSQ; Nolen-Hoeksema and Morrow 1991). The rumination subscale (10 items) represents thoughts and behaviours that maintain the focus on emotions (e.g., "When I'm feeling sad, I think about the other times I felt that way"). Items are rated on a five-point Likert type scale (i.e., $1=$ never, $2=$ almost never, $3=$ sometimes, $4=$ often, $\quad$ and $5=$ always). Reliability of the CRSS in terms of internal consistency is good $(\alpha=.81)$ and validity is adequate to good (Muris et al. 2004; Ziegert and Kistner 2002).

The stress-reactive rumination scale for children (SRRSC) is a downward extension of the same scale developed for adults (SRRS; Robinson 1997; Robinson and Alloy 2003). The SRRS-C aims to measure the frequency of negative thoughts about the negative inferences following stressful events (e.g., "I think about how the stressful event was totally my fault"). The SRRS-C consists of nine items and participants are instructed to score the frequency of each item on a four-point Likert type scale (i.e., $1=$ almost never, $2=$ sometimes, $3=$ often, $4=$ almost all the time). Reliability and discriminant validity of the adult version of the SRRS are acceptable (Robinson and Alloy 2003). The child version of the SRRS was translated into Dutch, and subsequently back translated by a native English speaker and was then approved by the original authors.

The Penn state worry questionnaire for children and adolescents (PSWQ-C; Chorpita et al. 1997; Dutch version: Muris et al. 2004) is a self-report questionnaire which aims to measure the tendency to worry in an excessive and uncontrollable way (e.g., "I am really bothered by the worrying I do" and "I really worry about things"). Items are scored on a four-point Likert type rating scale (i.e., $0=$ never, $1=$ seldom, $2=$ often, $3=$ always). The PSWQ-C is reliable in terms of internal consistency and possesses high convergent and discriminant validity (Muris et al. 2004). Test-retest stability is good (Chorpita et al. 1997). 


\section{Depressive Symptoms}

The children's depression inventory (CDI; Kovacs 1981; Dutch version: Timbremont and Braet 2001, 2002) is based on the Beck depression inventory for adults. The CDI is a widely used self-report questionnaire which aims to measure the level of depressive symptoms in children from 7 to 17 years old. It consists of 27 items, covering feelings of sadness, self-guilt, loss of appetite, insomnia, and adjustment to school. For each item, three statements are given. The subject has to choose one of three statements (e.g., "I am sad sometimes/I am often sad/I am always sad") that represents best how he or she has been feeling the last 2 weeks. Reliability in terms of internal consistency is good and the convergent validity of the $\mathrm{CDI}$ is supported. The $\mathrm{CDI}$ has some overlap with anxiety symptoms which reduces the discriminant validity of the CDI (Timbremont and Braet 2001).

\section{Anxiety Symptoms}

The trait version of the Spielberger state-trait anxiety inventory for children (STAI-TC; Spielberger et al. 1973; Dutch version: Bakker et al. 1989) is based on the STAI for adults (Spielberger et al. 1970). The STAI-TC consists of 20 items that aim to measure trait anxiety (e.g., "I am afraid to do things wrong"). Items are rated on a three-point Likert type scale (i.e., $1=$ almost never, $2=$ sometimes, $3=$ often). Reliability and convergent validity of the STAI-TC are good, but the discriminant validity remains questionable due to overlap with depressive symptoms (Muris et al. 2002).

\section{Statistical Analysis}

The data were analysed using SPSS version 13.0. For individuals with $<10 \%$ missing on values of a single self-report measure, a regression technique was used to impute the missing values by estimating the value on the basis of the scores of that individual on the remaining items, as well as on the scores of others on the item for which a score was missing. For the factor analyses, data from two samples were combined to obtain a sufficient number of participants to do factor analysis in children and adolescents separately. A principal factor analysis with oblimin rotation (which allows the obtained factors to be intercorrelated) was carried out on the items of the SRRS-C, the rumination scale of the CRSS and the PSWQ-C, separately for the two age categories of 10-13 and 14-18. In order to determine the number of factors to retain, we relied on parallel analysis (O'Connor 2000), which is considered a sophisticated procedure for selecting the number of factors in a factor analysis (e.g., Hayton et al. 2004). The advantage of parallel analysis over other factor retention methods is that it corrects for the effects of sampling error. By means of parallel analysis, random eigenvalues are generated from random data, based on the number of variables and sample size of the data one wishes to analyse. Subsequently, the random eigenvalues have to be compared to the eigenvalues produced by the factor analysis. The number of factors to retain is determined by the number of eigenvalues, for which the real eigenvalue obtained by factor analysis is greater than the random eigenvalue. When an eigenvalue generated from the exploratory factor analysis is higher than the random eigenvalue generated from the parallel analysis, it can be assumed that the eigenvalue represents a real factor, that accounts for more variance than a parallel component based on random data (see Hayton et al. 2004). Further, the screeplots were inspected visually. Subsequently, the internal consistency of the obtained dimensions of repetitive thinking was determined by computing reliability coefficients (Cronbach's alpha).

For the second aim of this study, analyses were carried out on data from sample one, for which measures of depressive and anxiety symptoms were available. First, to examine the concurrent criterion validity, zero-order correlations between the forms of repetitive thought, and symptoms of depression and anxiety were computed. Second, to examine the relative predictive validity of the dimensions of negative thinking, we computed partial correlation coefficients between each type of negative thinking and symptoms of depression, controlling for the other two types of negative thinking, age, gender, and anxiety symptoms. For example, in the computation of the partial correlation between depressive symptoms and stress-reactive rumination, we controlled for worry, emotion-focused rumination, age, gender, and symptoms of anxiety. In a similar vein, we computed partial correlations between each type of negative thinking and anxiety symptoms, controlling for the other two types of negative thinking, age, gender, and depressive symptoms. As an aside, gender differences on the self-report measures and differences on the total scores of the measures for those who completed the questionnaires by computer or paper were tested by means of $t$-tests over the whole sample.

\section{Results}

Joint Factor Analysis on SRRS-C, CRSS, and PSWQ-C Items

An exploratory joint principal factor analysis (PFA) was carried out on all 33 items of the SRRS-C, CRSS, and PSWQ-C, in a sample of children aged 10-13 $(N=1,078)$, and in a sample of adolescents aged $14-18(N=528)$. Parallel analysis was used as a method to determine the number of factors to retain. For the sample aged 10-13, the first five eigenvalues obtained with PFA were 11.41, 2.61, 1.60, 1.06, and 1.02 , while the random eigenvalues obtained by means 
of parallel analysis were $1.38,1.33,1.29,1.26$, and 1.24 . Thus, three factors should be retained according to the parallel test. In addition, the scree test supported a three-factor model as a clear break was found after the third factor. Bartlett's tests for sphericity were significant and all MSA values were higher than .80 , indicating that the variables involved correlate with each other and with more than one variable, which means that factor analysis can be applied to these data in a meaningful way. The communalities ranged from .24 to .53 , indicating that all items explained a unique part of the variance across all factors. The three-factor model explained $42.1 \%$ of the variance. The first factor consisted of all PSWQ-C items and was therefore labelled the "worryscale'; the second factor consisted of CRSS items representing the 'emotion-focused rumination scale', whereas all SRRS-C items loaded on the third factor, the 'stress-reactive rumination scale'. None of the items loaded significantly (i.e., >.30) on more than one factor. Factor loadings of all items are shown in Table 1. The reliability in terms of internal consistency of the three dimensions was good

Table 1 Factor loadings (pattern coefficients) as obtained by principal factor analysis with Oblimin rotation of the PSWQ-C, SRRS-C and CRSS

\begin{tabular}{|c|c|c|c|c|c|c|c|}
\hline \multirow[t]{2}{*}{ Item } & \multirow[t]{2}{*}{ Item description } & \multicolumn{2}{|c|}{ Factor 1} & \multicolumn{2}{|c|}{ Factor 2} & \multicolumn{2}{|c|}{ Factor 3} \\
\hline & & $\leq 13$ & $\geq 14$ & $\leq 13$ & $\geq 14$ & $\leq 13$ & $\geq 14$ \\
\hline PSWQ-C 10 & I have been a worrier all my life & .77 & .77 & -.10 & -.01 & .01 & -.0 \\
\hline PSWQ-C 13 & I worry all the time & .75 & .86 & -.05 & -.08 & .00 & -.07 \\
\hline PSWQ-C 6 & I'm always worrying about something & .74 & .83 & -.04 & -.07 & -.03 & \\
\hline PSWQ-C 2 & I really worry about things & .72 & .73 & .06 & .06 & -.07 & -.00 \\
\hline PSWQ-C 12 & Once I start worrying, I can't stop & .69 & .65 & .00 & .07 & .01 & \\
\hline PSWQ-C 9 & I worry about everything & .68 & .79 & -.08 & .01 & .08 & -.11 \\
\hline PSWQ-C 7 & I find it hard to quit worrying when I want to & .67 & .53 & .09 & .07 & -.08 & .1 \\
\hline PSWQ-C 3 & I worry about a lot of things & .66 & .67 & .02 & .03 & .08 & .0 \\
\hline PSWQ-C 4 & I know I shouldn't worry so much, but I just can't help it & .63 & .72 & .12 & .08 & -.02 & \\
\hline PSWQ-C 11 & I notice that I have been worrying about things & .62 & .63 & .03 & .10 & .13 & .1 \\
\hline PSWQ-C 5 & When I'm under pressure I worry a lot & .59 & .58 & .12 & .08 & -.02 & \\
\hline PSWQ-C 1 & I'm really bothered by the worrying I do & .54 & .63 & .10 & .15 & .09 & \\
\hline PSWQ-C 8 & As soon as I finish something, I start worrying about all kind of other things & .52 & .64 & -.04 & -.05 & .09 & \\
\hline PSWQ-C 14 & I'm always worrying about the things I need to do, until they're finished & .45 & .49 & .12 & .12 & .11 & \\
\hline CRSS 19 & When I'm feeling sad, I think about how I feel & -.01 & -.02 & .71 & .79 & -.00 & \\
\hline CRSS 13 & When I'm feeling sad, I think about why it is I feel this way & -.09 & -.06 & .68 & .67 & -.05 & \\
\hline CRSS 4 & When I'm feeling sad, I withdraw and think about why I feel that way & .09 & .10 & .61 & .70 & -.07 & -.0 \\
\hline CRSS 16 & When I'm feeling sad, I think about the things that have happened over and over again & .11 & .14 & .60 & .58 & .04 & \\
\hline CRSS 20 & When I'm feeling sad, I think about something that happened and wish it had gone better & -.08 & .02 & .59 & .51 & .19 & \\
\hline CRSS 7 & When I'm feeling sad, I isolate myself to think about my feelings & .05 & -.01 & .58 & .76 & -.01 & -.12 \\
\hline CRSS 11 & $\begin{array}{l}\text { When I'm feeling sad, I think about the other times that things didn't go the way } \\
\text { I wanted }\end{array}$ & .04 & .17 & .56 & .43 & .02 & .1 \\
\hline CRSS 2 & When I'm feeling sad, I think about that I should have done things differently & .06 & .05 & .50 & .44 & .14 & .2 \\
\hline CRSS 1 & When I'm feeling sad, I think about the other times that I felt this way & .03 & .19 & .49 & .33 & .12 & .2 \\
\hline CRSS 8 & When I'm feeling sad, I think: why can't I stop feeling this way? & .05 & .21 & .47 & .46 & .07 & .1 \\
\hline SRRS-C 4 & I think about how terrible the stressful event was & -.00 & .15 & -.08 & -.11 & .76 & .6 \\
\hline SRRS-C 5 & I think about the stressful event and wish it had gone better & -.02 & .03 & .04 & .01 & .68 & .7 \\
\hline SRRS-C 7 & I think about the causes of the stressful event & -.04 & -.11 & .01 & .11 & .60 & .5 \\
\hline SRRS-C 6 & I think about how the stressful event will negatively affect my life & .08 & .08 & .02 & -.01 & .59 & .6 \\
\hline SRRS-C 2 & I think about what the occurrence of the stressor means about me & .03 & .12 & .04 & .11 & .53 & .4 \\
\hline SRRS-C 1 & I think about how the stressful event was all my fault & .15 & .24 & .03 & -.04 & .50 & .5 \\
\hline SRRS-C 9 & I think about how things like this always happen to me & .17 & .21 & .04 & .04 & .49 & .4 \\
\hline SRRS-C 3 & I think about how things could have gone differently & -.01 & -.02 & .16 & .09 & .48 & .6 \\
\hline SRRS-C 8 & I think about how important the stressful event is for me & .00 & -.07 & .05 & .02 & .46 & \\
\hline
\end{tabular}

PSWQ-C = worry; CRSS = emotion-focused rumination; SRRS-C = stress-reactive rumination. Factor loadings on the corresponding factors are displayed in "Italic" 
(stress-reactive rumination: $\alpha=.84$, worry: $\alpha=.92$, and emotion-focused rumination: $\alpha=.86$ ).

The factor analysis in the adolescent sample yielded comparable results. The first five eigenvalues obtained by factor analysis were $13.51,2.64,1.48, .99$, and .94, while the first five random eigenvalues obtained by means of parallel analysis were $1.56,1.48,1.43,1.38$, and 1.34. This means that also in the sample of adolescents, a three-factor structure with factors 'worry', 'stress-reactive rumination', and 'emotionfocused rumination' could be retained. Factor loadings are displayed in Table 1. All items loaded significantly (>.30) on their corresponding factors. Communalities ranged from .27 to .63 . The three-factor model explained $48.8 \%$ of the variance. The reliability in terms of internal consistency of the three dimensions was good (stress-reactive rumination: $\alpha=.85$, worry: $\alpha=.94$, and emotion-focused rumination: $\alpha=.90$ ). Noteworthy to mention, we also carried out the factor analysis over the total group of children and adolescents aged 10-18 years $(N=1,606)$. Results were similar to those obtained in the child (10-13) and adolescent (14-18) samples separately: a three-factor structure emerged ('worry', 'stressreactive rumination' and 'emotion-focused rumination'), with all items loading significantly $(>.30)$ and exclusively on their corresponding factor.

\section{General Statistics, Gender Differences, and Reliability}

Descriptive statistics of the scales used in sample one and two are presented in Table 2. A number of remarks with respect to these findings need to be made. First, gender differences examined by means of $t$-tests showed that girls had significantly higher scores than boys on all questionnaires except for the CDI (alpha at .05). Second, a series of $t$-tests showed that individuals who completed the questionnaires on the internet had significantly higher scores on the CRSS and PSWQ (alpha at .05) compared to those who used the paper-and-pencil version. Third, reliability in terms of internal consistency is adequate to good and is displayed in Table 2. Finally, total scores on the CDI were positively skewed and showed positive kurtosis and were therefore subjected to a root square transformation which 'normalised' the total scores of these variables.

\section{Discriminant Validity of the SRRS-C}

Stress-reactive rumination (SRRS-C) correlated highly with worry (PSWQ-C), $r=.70$, and with emotion-focused rumination (CRSS), $r=.65$ (Table 3 ). When correcting the correlation coefficients for attenuation (unreliability), the correlation coefficient between SRRS-C and PSWQ-C was .77 and the correlation coefficient between SRRS-C and CRSS was .74. Thus, correcting for the attenuation effect did not result in a nearly perfect association, which indicates that the factors measure distinct constructs. Thus, the SRRS-C, PSWQ-C, and the CRSS are three forms of repetitive thinking that have a certain degree of overlap but can still be distinguished.

\section{Concurrent Criterion Validity and Relative Predictive Validity}

Table 3 presents the zero-order correlation coefficients and partial correlation coefficients (in parentheses) between all self-report measures. As can be seen in Table 3, the three forms of repetitive thinking all show moderate to high associations with depressive and anxiety symptoms. The strongest relationships were found for worry (PSWQ-C), followed by stress-reactive rumination (SRRS-C), and

Table 2 Descriptive statistics and internal consistency (alpha) for all questionnaires for sample $1(N=779-805)$ and sample $2(N=799-801)$, for the total sample, and for girls and boys separately

\begin{tabular}{|c|c|c|c|c|c|c|c|c|c|}
\hline & \multicolumn{3}{|c|}{ Total sample } & \multicolumn{2}{|l|}{ Girls } & \multicolumn{2}{|c|}{ Boys } & \multicolumn{2}{|c|}{ Gender difference } \\
\hline & $M$ & SD & Alpha & $M$ & SD & $M$ & SD & $t$ & $p$ \\
\hline \multicolumn{10}{|l|}{ Sample 1} \\
\hline Depression (CDI) & 8.0 & 6.3 & .87 & 8.3 & 6.6 & 7.5 & 5.9 & 1.7 & .084 \\
\hline Trait anxiety (STAI-TC) & 30.5 & 7.9 & .91 & 31.6 & 8.0 & 28.9 & 7.4 & 4.7 & $<.001$ \\
\hline Stress-reactive rumination (SRRS-C) & 16.7 & 5.1 & .88 & 17.2 & 5.2 & 16.0 & 4.8 & 3.2 & .002 \\
\hline Worry (PSWQ-C) & 12.0 & 8.1 & .94 & 13.0 & 8.1 & 10.7 & 7.8 & 3.8 & $<.001$ \\
\hline Emotion-focused rumination (CRSS) & 16.4 & 7.7 & .87 & 17.5 & 7.3 & 14.9 & 7.9 & 4.8 & $<.001$ \\
\hline Age & 12.4 & 1.9 & - & 12.4 & 1.9 & 12.3 & 1.7 & 1.2 & .221 \\
\hline \multicolumn{10}{|l|}{ Sample 2} \\
\hline Stress-reactive rumination (SRRS-C) & 16.7 & 4.8 & .82 & 17.1 & 5.1 & 16.2 & 4.5 & 2.8 & .005 \\
\hline Worry (PSWQ-C) & 12.4 & 7.2 & .92 & 14.2 & 7.4 & 10.3 & 6.4 & 8.3 & $<.001$ \\
\hline Emotion-focused rumination (CRSS) & 15.6 & 8.0 & .88 & 17.7 & 7.7 & 13.2 & 7.7 & 8.0 & $<.001$ \\
\hline
\end{tabular}

$C D I$ children's depression inventory, STAI-TC Spielberger state-trait anxiety inventory for children (trait version), SRRS-C stress-reactive rumination scale for children, $P S W Q-C$ Penn state worry questionnaire for children, $C R S S$ children's response styles scale 
Table 3 Associations between all self-report measures $(N=785-805)$

\begin{tabular}{|c|c|c|c|c|c|c|}
\hline & 1. & 2. & 3. & 4. & 5. & 6. \\
\hline 1. Depression (CDI) & - & & & & & \\
\hline 2. Trait anxiety (STAI-TC) & $.69^{*}$ & - & & & & \\
\hline 3. Stress-reactive rumination (SRRS-C) & $.59 *\left(.16^{*}\right)$ & $.68 *(.17 *)$ & - & & & \\
\hline 4. Worry (PSWQ-C) & $.62 *(.11 *)$ & $.77 *(.46 *)$ & $.70 *$ & - & & \\
\hline 5. Emotion-focused rumination (CRSS) & $.44 *(-.01)$ & $.55^{*}(.06)$ & $.65^{*}$ & $.58^{*}$ & - & \\
\hline 6. Age & .12 & .11 & $.17 *$ & .14 & .12 & - \\
\hline 7. Gender & .05 & $.17 *$ & $.11 *$ & $.14^{*}$ & $.17 *$ & .04 \\
\hline
\end{tabular}

Partial correlations coefficients are presented in parentheses

CDI children's depression inventory, STAI-TC Spielberger state-trait anxiety inventory for children (trait version), SRRS-C stress-reactive rumination scale for children, $P S W Q-C$ Penn state worry questionnaire for children, CRSS children's response styles scale

$* p<.005$

emotion-focused rumination (CRSS). With respect to the partial correlation coefficients between the three forms of repetitive thinking on the one hand, and symptoms of depression and anxiety on the other hand, worry emerged as a significant and strong predictor of anxiety symptoms, whereas modest relations were found between worry and depression, and between stress-reactive rumination and symptoms of anxiety and depression. ${ }^{1}$ Emotion-focused rumination was no longer associated with either depression or anxiety symptoms when worry and stress-reactive rumination were controlled. One may argue that controlling for highly interrelated variables may affect the findings with respect to partial correlations due to multicollinearity of the independent variables. Therefore, we ran a series of linear regression analyses with scores of the depression and anxiety scales as the dependent variables and the three forms of repetitive thinking as independent variables. Variance inflation factors (VIF) ranged between 1.83 and 2.93 indicating that multicollinearity did not influence the results.

\section{Discussion}

The current study sought to examine three forms of negative repetitive thinking in children and adolescents. More specifically, this study addressed (1) the degree to which stress-

\footnotetext{
${ }_{1}$ An anonymous reviewer suggested controlling for negative cognitive style in order to ensure that the uncontrolled confound of negative cognitive style was not driving the associations between stressreactive rumination and depressive and anxiety symptoms. Negative cognitive style is a composite score of scales measuring the inferences about the globality and stability of the causes of a negative event, inferences about the consequences of an event, and inferences about the self (Hankin and Abramson 2002). When controlling for negative cognitive style, the partial correlations between stress-reactive rumination and symptoms of depression and anxiety remained significant $(\mathrm{pr}=.13, p<.001$, and $\mathrm{pr}=.16, p<.001$, respectively).
}

reactive rumination can be differentiated from other forms of repetitive thinking, such as emotion-focused rumination and worry in children and adolescents, and (2) the associations between the various indices of repetitive thinking and symptoms of anxiety and depression. The stress-reactive rumination scale for children was developed for the purpose of this study and is a downward extension of the stress-reactive rumination scale used in adults (Robinson and Alloy 2003).

A joint exploratory factor analysis on items of three measures tapping stress-reactive rumination (SRRS-C), emotion-focused rumination (CRSS), and worry (PSWQ-C) yielded a three-factor model both in children aged between 10 and 13 and adolescents aged between 14 and 18 years. Taking into account that the measures are intercorrelated, the results show that three forms of repetitive negative thinking can be distinguished in both age groups. These findings are in line with and add to previous findings concerning the degree to which rumination and worry can be differentiated (e.g., Fresco et al. 2002; Muris et al. 2004). More specifically, the results indicate that stressreactive rumination is a unique form of repetitive thinking in addition to emotion-focused rumination and worry. Another implication of the finding that age did not seem to moderate the factor structure is that repetitive negative thinking as a vulnerability to depression can be applied to child and adolescent samples. These findings are in line with past research (e.g., Abela et al. 2007). However, it should be kept in mind that these findings may reflect the wording of the materials used such that items with "worry" in their description tend to group together, whereas items with "feeling sad", "think about" or "stressful events" in their description tend to group together as well. Despite this limitation of the use of questionnaires, the data provide evidence that stress-reactive rumination is independent from emotion-focused rumination and worry.

All three forms of repetitive negative thinking showed positive and significant associations with symptoms of 
depression and anxiety. In general, worry showed the strongest associations with depression and anxiety symptoms, followed by stress-reactive rumination. In general, rumination as well as worry were equally strongly related to depressive symptoms as to anxiety symptoms, adding to past research showing that rumination and worry are not specific to depression and anxiety symptoms, respectively (e.g., Blagden and Craske 1996; Fresco et al. 2002; Molina et al. 1998; Muris et al. 2005; Nolen-Hoeksema 2000; Roberts et al. 1998; Sarin et al. 2005; Starcevic 1995; Watkins 2004). These findings support the viewpoint that repetitive negative thinking that takes the form of emotionfocused rumination, stress-reactive rumination, or worry, can be seen as a transdiagnostic variable (e.g., Harvey et al. 2004).

In examining the relative contribution of the three forms of repetitive negative thinking controlling for the other two, worry and stress-reactive rumination were significantly associated with depression and anxiety symptoms. Thus, despite the significant zero-order correlation coefficients between emotion-focused rumination and symptoms of anxiety and depression, emotion-focused rumination was no longer significant when controlling for the effects of stress-reactive rumination and worry. The finding that emotion-focused rumination did not account for a significant portion of the variance in depression was not in line with our hypothesis. However, it does add to previous research showing that worry ruled out emotion-focused rumination as a predictor of depressive and anxiety symptoms (Muris et al. 2004). From a theoretical perspective, the response styles theory posits that emotionfocused rumination is implicated in the duration of negative mood and includes items that refer to the situation in which one is already feeling depressed (Nolen-Hoeksema 1991). Stress-reactive rumination on the other hand is theoretically linked to the onset of depressive symptoms (see Robinson and Alloy 2003), while the occurrence of worry also is not necessarily dependent on a sad mood state. Therefore, stress-reactive rumination and worry may be stronger predictors of depressive symptoms than emotion-focused rumination in a non-clinical sample as the current one, where significant negative mood states may be less prevalent. The role of emotion-focused rumination in clinical samples of depressed children suffering from negative mood states needs investigation.

The findings of the present study underscore the importance of targeting not only the content of thoughts, but also the thought process in interventions with depressed and anxious youth. For example, in cognitive therapy, it may be important to specifically challenge ruminative or worrisome thoughts. In this light, one may also wish to consider challenging positive (e.g., "Worry/rumination helps me overcome my problems") and negative metacognitions about worry and rumination (e.g., "Other children will reject me if I worry/ruminate that much" or "I may go crazy if I keep on worrying/ruminating") and to use strategies such as postponing worrying or rumination to test the (negative) metacognition that one has no control over repetitive thinking (see Wells and Papageorgiou 2004). Other approaches that have received a lot of attention recently are mindfulness-based interventions. These might be especially effective in reducing repetitive thought processes, by learning to emotionally disengage from recurrent negative thoughts instead of letting them affect one's mood. An example of a mindfulness based intervention is mindfulness based cognitive therapy (Segal et al. 2002).

This study has some limitations that need to be addressed. First, the study was cross-sectional in nature making it impossible to draw conclusions about causeeffect relations. More specifically, the cross-sectional nature of the study makes it difficult to discern whether high levels of repetitive thinking result in more anxiety and depression or whether high levels of anxiety and depression may lead to more repetitive thinking. Studies that employ prospective intervals are needed to examine the predictive value and the stability of the various forms of repetitive thinking (see Hankin 2008). Experimental studies in which repetitive thinking can be manipulated are also warranted to determine the causal nature of repetitive thinking in depressive and anxiety symptoms. Second, the sample used in the current study was predominantly white European, which may limit the generalisability of the findings to other cultures. Furthermore, a minority (25\%) of the approached children and adolescents decided to participate. It is possible that this sample is biased in some way. However, as we did not gather demographic information about variables such as ethnicity or socio-economic status, it is not possible to compare the final sample to expected rates.

Despite these limitations, the results of the current study seem to indicate that stress-reactive rumination can be uniquely identified as a form of repetitive thinking in addition to emotion-focused rumination and worry. Future research should be aimed at bringing together various variables that are thought to play a role in juvenile depression and anxiety such as various forms of repetitive thinking, negative cognitive styles, and puberty. The inclusion of life events and daily hassles makes it possible to contribute to a further understanding of depression and anxiety in youth within a diathesis-stress account.

Acknowledgments This study was supported by an NWO Social Sciences Research VENI Grant No. 451-05-019, awarded to Dr. Jeffrey Roelofs.

Open Access This article is distributed under the terms of the Creative Commons Attribution Noncommercial License which 
permits any noncommercial use, distribution, and reproduction in any medium, provided the original author(s) and source are credited.

\section{References}

Abela, J. R. Z., Aydin, C., \& Auerbach, R. (2007). Responses to depression in children: Reconceptualizing the relation among response styles. Journal of Abnormal Child Psychology, 35, 913-927.

Abela, J. R. Z., Brozina, K., \& Haigh, E. (2002). An examination of the response styles theory of depression in third and seventh grade children: A short term longitudinal study. Journal of Abnormal Child Psychology, 30(5), 515-527.

Abela, J. R. Z., \& Hankin, B. L. (2008). Cognitive vulnerability to depression in children and adolescents: A developmental psychopathology perspective. In J. R. Z. Abela \& B. L. Hankin (Eds.), Handbook of depression in children and adolescents (pp. 35-78). New York: Guilford.

Abela, J. R. Z., Vanderbilt, E., \& Rochon, A. (2004). A test of the integration of the response styles and social support theories of depression in third and seventh grade children. Journal of Social and Clinical Psychology, 23(5), 653-674.

Abramson, L. Y., Metalsky, G., \& Alloy, L. B. (1989). Hopelessness depression: A theory-based subtype of depression. Psychological Review, 96(2), 358-372.

Alloy, L., Abramson, L., Hogan, M., Whitehouse, W., Rose, D., Robinson, M., et al. (2000). The Temple-Wisconsin cognitive vulnerability to depression project: Lifetime history of axis I psychopathology in individuals at high and low cognitive risk for depression. Journal of Abnormal Psychology, 109(3), 403-418.

American Psychiatric Association. (2000). Diagnostic and statistical manual of mental disorders (5th ed.). Washington, DC: APA.

Bakker, F., van Wieringen, P., van der Ploeg, H., \& Spielberger, C. (1989). De Zelf-Beoordelings-Vragenlijst voor kinderen. Lisse: Swets \& Zeitlinger.

Beck, A. (1967). Depression: Clinical, experimental and theoretical aspects. New York: Harper \& Row.

Blagden, J., \& Craske, M. (1996). Effects of active and passive rumination and distraction: A pilot replication with anxious mood. Journal of Anxiety Disorders, 10(4), 243-252.

Borkovec, T. (1994). The nature, functions, and origins of worry. In G. Davey \& F. Tallis (Eds.), Worrying: Perspectives on theory, assessment and treatment (pp. 5-33). Chichester: Wiley.

Borkovec, T., Robinson, E., Pruzinsky, T., \& DePree, J. (1983). Preliminary exploration of worry: Some characteristics and processes. Behaviour Research and Therapy, 21(1), 9-16.

Burwell, R., \& Shirk, S. (2007). Subtypes of rumination in adolescence: Associations between brooding, reflection, depressive symptoms, and coping. Journal of Clinical Child and Adolescent Psychology, 36(1), 56-65.

Calmes, C., \& Roberts, J. (2007). Repetitive thought and emotional distress: Rumination and worry as prospective predictors of depressive and anxious symptomatology. Cognitive Therapy and Research, 30, 343-356.

Chorpita, B., Tracey, S., Brown, T., Collica, T., \& Barlow, D. (1997). Assessment of worry in children and adolescents: An adaptation of the Penn State Worry Questionnaire. Behaviour Research and Therapy, 35(6), 569-581.

Dugas, M., Freeston, M., Ladouceur, R., Rhéaume, J., Provencher, M., \& Boisvert, J.-M. (1998). Worry themes in primary GAD, secondary GAD, and other anxiety disorders. Journal of Anxiety Disorders, 12(3), 253-261.
Fresco, D., Frankel, A., Mennin, D., Turk, C., \& Heimberg, R. (2002). Distinct and overlapping features of rumination and worry: The relationship of cognitive production to negative affective states. Cognitive Therapy and Research, 26(2), 179-188.

Hankin, B. (2008). Stability of cognitive vulnerabilities to depression: A short-term prospective multiwave study. Journal of Abnormal Psychology, 117(2), 324-333.

Hankin, B. L., \& Abramson, L. Y. (2002). Measuring cognitive vulnerability to depression in adolescence: Reliability, validity, and gender differences. Journal of Clinical Child and Adolescent Psychology, 31, 491-504.

Harvey, A., Watkins, E., Mansell, W., \& Shafran, R. (2004). Cognitive behavioral processes across psychological disorders: A transdiagnostic approach to research and treatment. Oxford: Oxford University Press.

Hayton, J. C., Allen, D. G., \& Scarpello, V. (2004). Factor retention decisions in exploratory factor analysis: A tutorial on parallel analysis. Organizational Research Methods, 7(2), 191-205.

Hong, R. (2007). Worry and rumination: Differential associations with anxious and depressive symptoms and coping behavior. Behaviour Research and Therapy, 45, 277-290.

Kovacs, M. (1981). Rating scales to assess depression in school-aged children. Acta Paedopsychiatrica, 46, 305-315.

Leen-Feldner, E., Feldner, M., Tull, M., Roemer, L., \& Zvolensky, M. (2006). An examination of worry in relation to anxious responding to voluntary hyperventilation among adolescents. Behaviour Research and Therapy, 44, 1803-1809.

Lyubomirsky, S., \& Tkach, C. (2004). The consequences of dysphoric rumination. In C. Papageorgiou \& A. Wells (Eds.), Depressive rumination: Nature, theory, and treatment (pp. 21-41). Chichester: Wiley.

Molina, S., Borkovec, T., Peasley, C., \& Person, D. (1998). Content analysis of worrisome streams of consciousness in anxious and dysphoric participants. Cognitive Therapy and Research, 22(2), 109-123.

Muris, P. (2007). Normal and abnormal fear and anxiety in children and adolescents. Oxford: Elsevier.

Muris, P., Merckelbach, H., Ollendick, T., King, N., \& Bogie, N. (2002). Three traditional and three new childhood anxiety questionnaires: Their reliability and validity in a normal adolescent sample. Behaviour Research and Therapy, 40, 753-772.

Muris, P., Roelofs, J., Meesters, C., \& Boomsma, P. (2004). Rumination and worry in nonclinical adolescents. Cognitive Therapy and Research, 28(4), 539-554.

Muris, P., Roelofs, J., Rassin, E., Franken, I., \& Mayer, B. (2005). Mediating effects of rumination and worry on the links between neuroticism, anxiety and depression. Personality and Individual Differences, 39, 1105-1111.

Nolen-Hoeksema, S. (1987). Sex differences in unipolar depression: Evidence and theory. Psychological Bulletin, 101(2), 259-282.

Nolen-Hoeksema, S. (1991). Responses to depression and their effects on the duration of depressive episodes. Journal of Abnormal Psychology, 100(4), 569-582.

Nolen-Hoeksema, S. (1998). Ruminative coping with depression. In J. Heckhausen \& C. Dweck (Eds.), Motivation and self-regulation across the life span (pp. 237-256). Cambridge: Cambridge University Press.

Nolen-Hoeksema, S. (2000). The role of rumination and depressive disorders and mixed anxiety/depressive symptoms. Journal of Abnormal Psychology, 109(3), 504-511.

Nolen-Hoeksema, S., \& Morrow, J. (1991). A prospective study of depression and posttraumatic stress symptoms after a natural disaster: The 1989 Loma Prieta earthquake. Journal of Personality and Social Psychology, 61(1), 115-121.

O'Connor, B. (2000). SPSS and SAS programs for determining the number of components using parallel analysis and Velicer's 
MAP test. Behavior Research Methods, Instrumentation, and Computers, 32, 396-402.

Papadakis, A. A., Prince, R. A., Jones, N. P., \& Strauman, T. J. (2006). Self-regulation, rumination, and vulnerability to depression in adolescent girls. Development and Psychopathology, 18, $815-829$.

Perrin, S., \& Last, C. (1997). Worrisome thoughts in children clinically referred for anxiety disorder. Journal of Clinical Child Psychology, 26(2), 181-189.

Roberts, J., Gilboa, E., \& Gotlib, I. (1998). Ruminative response style and vulnerability to episodes of dysphoria: Gender, neuroticism, and episode duration. Cognitive Therapy and Research, 22(4), 401-423.

Robinson, M. (1997). The role of negative inferential style and stressreactive rumination on negative inferences in the etiology of depression: Empirical investigation and clinical implications. Unpublished doctoral dissertation, Temple University.

Robinson, M., \& Alloy, L. (2003). Negative cognitive styles and stress-reactive rumination interact to predict depression: A prospective study. Cognitive Therapy and Research, 27(3), 275-292.

Roemer, L., \& Borkovec, T. D. (1993). Worry: Unwanted cognitive activity that controls unwanted somatic experience. In D. M. Wegner \& J. W. Pennebaker (Eds.), Handbook of mental control (pp. 220-238). Englewood Cliffs, NJ: Prentice Hall.

Sarin, S., Abela, J., \& Auerbach, R. (2005). The response styles theory of depression: A test of specificity and causal mediation. Cognition and Emotion, 19(5), 751-761.

Schwartz, J., \& Koenig, L. (1996). Response styles and negative affect among adolescents. Cognitive Therapy and Research, 20(1), 13-36.

Segal, Z., Williams, J., \& Teasdale, J. (2002). Mindfulness-based cognitive therapy for depression. A new approach to preventing relapse. New York: Guilford.

Segerstrom, S., Tsao, J., Alden, L., \& Craske, M. (2000). Worry and rumination: Repetitive thought as a concomitant and predictor of negative mood. Cognitive Therapy and Research, 24(6), 671688.
Spielberger, C., Edwards, D., Lushene, R., Montuori, J., \& Platzek, D. (1973). State-trait anxiety inventory for children. Palo Alto, CA: Consulting Psychologists.

Spielberger, C., Gorsuch, R., \& Lushene, R. (1970). STAI manual for the state-trait anxiety inventory. Palo Alto, CA: Consulting Psychologists.

Starcevic, V. (1995). Pathological worry in major depression: A preliminary report. Behaviour Research and Therapy, 33(1), 55-56.

Timbremont, B., \& Braet, C. (2001). Psychometrische evaluatie van de Nederlandstalige Children's Depression Inventory [Psychometric evaluation of the Dutch Children's Depression Inventory]. Gedragstherapie, 34(3), 229-242.

Timbremont, B., \& Braet, C. (2002). Children's depression inventory: Nederlandstalige versie [Children's depression inventory: Dutch version]. Lisse: Swets \& Zeitlinger.

Timbremont, B., Braet, C., \& Dreessen, L. (2004). Assessing depression in youth: Relation between the Children's Depression Inventory and a structured interview. Journal of Clinical Child and Adolescent Psychology, 33, 149-157.

Watkins, E. (2004). Appraisals and strategies associated with rumination and worry. Personality and Individual Differences, 37, 679-694.

Watkins, E. (2008). Constructive and unconstructive repetitive thought. Psychological Bulletin, 134(2), 163-206.

Watkins, E., Moulds, M., \& Mackintosh, B. (2005). Comparisons between rumination and worry in a non-clinical population. Behaviour Research and Therapy, 43, 1577-1585.

Weems, C., Silverman, W., \& La Greca, A. (2000). What do youth referred for anxiety problems worry about? Worry and its relation to anxiety and anxiety disorders in children and adolescents. Journal of Abnormal Child Psychology, 28(1), 63-72.

Wells, A., \& Papageorgiou, C. (2004). Metacognitive therapy for depressive rumination. In C. Papageorgiou \& A. Wells (Eds.), Depressive rumination: Nature, theory and treatment (pp. 259273). Chichester: Wiley.

Ziegert, D., \& Kistner, J. (2002). Response styles theory: Downward extension to children. Journal of Clinical Child and Adolescent Psychology, 31(3), 325-334. 